\title{
Black liquor-based hydrogen and power co-production: Combination of supercritical water gasification and syngas chemical looping
}

\author{
Arif Darmawan $^{\mathrm{a}, \mathrm{b}, *}$, Muhammad W. Ajiwibowo ${ }^{\mathrm{c}}$, Muhammad Kunta Biddinika $^{\mathrm{a}}$, Koji Tokimatsu $^{\mathrm{a}}$, \\ Muhammad Aziz ${ }^{\mathrm{d}, *}$ \\ ${ }^{a}$ Department of Transdisciplinary Science and Engineering, Tokyo Institute of Technology, 4259 Nagatsuta-cho, Midori-ku, Yokohama, Kanagawa 226-8503, Japan \\ ${ }^{\mathrm{b}}$ Agency for the Assessment and Application of Technology (BPPT), Puspiptek Serpong, Tangerang Selatan 15314, Indonesia \\ ${ }^{\mathrm{c}}$ Department of Mechanical Engineering, University of Indonesia, Depok 16424, Indonesia \\ ${ }^{\mathrm{d}}$ Institute of Industrial Science, The University of Tokyo, 4-6-1 Komaba, Meguro-ku, Tokyo 153-8505, Japan
}

\section{H I G H L I G H T S}

- $\mathrm{H}_{2}$ and power cogeneration system from black liquor is proposed.

- The system combines supercritical water gasification and syngas chemical looping.

- The available technologies of BL recovery are discussed and compared.

- Compared to other systems, the proposed system shows the highest overall efficiency of $82 \%$.

- The system is cleaner and more efficient with $75 \% \mathrm{CO}_{2}$ capture.

\section{A R T I C L E I N F O}

\section{Keywords:}

Black liquor

Integrated system

Hydrogen

Supercritical water gasification

Exergy recovery

Co-production

\begin{abstract}
A B S T R A C T
An integrated system to efficiently harvest energy from the waste produced in the pulp mill industry, namely black liquor (BL), is proposed and investigated. The proposed system mainly comprises the supercritical water gasification (SCWG) of BL and syngas chemical looping (SCL). In addition, to effectively minimize the circulation of heat throughout the system, and therefore optimize the energy efficiency, the process design and integration are conducted by simultaneously adopting the concepts of exergy recovery and process integration. The available technologies for electricity generation and hydrogen production from BL recovery are discussed and compared with the proposed system. In this study, hydrogen is set as the main output, while power is produced by utilizing the heat generated throughout the process. Process simulation is performed using a steady state process simulator Aspen Plus. Energy efficiency is classified into three categories: hydrogen production efficiency, power generation efficiency, and total energy efficiency. Compared to other BL recovery systems, the proposed integrated system combining SCWG and SCL processes seems to be very promising. The integrated system shows very high total energy efficiency and carbon capture of about $80 \%$ and $75 \%$, respectively.
\end{abstract}

\section{Introduction}

Biomass-based hydrogen $\left(\mathrm{H}_{2}\right)$ has been receiving considerable attention and could play a significant role as an energy carrier (secondary energy source) in the foreseeable future. As a secondary energy source, $\mathrm{H}_{2}$ is predicted to be very important in the future due to its advantages such as high energy density, high reactivity rate, overall cleanliness, very high flame speed during combustion, and various production routes [1-3]. Besides, hydrogen is abundant on earth, albeit in its oxidized state $\left(\mathrm{H}_{2} \mathrm{O}\right)$. Researches on producing $\mathrm{H}_{2}$ have attracted significant interest for a long time, and various technologies, such as gasification or pyrolysis at high temperature, oil/gas reforming, and water splitting by electrolysis, have been developed.

Since the biomass-based fuel must be sufficiently competitive with other energy sources, efficient routes from biomass should be investigated urgently. On an industrial scale, biomass waste, such as black liquor (BL) from pulp mill, has the energy potential for power and $\mathrm{H}_{2}$ generation [4]. The proper and efficient utilization of BL can reduce environmental impacts, as well as improve both the economic and energy values of the waste. However, as the moisture content of BL is very

\footnotetext{
* Corresponding authors at: Institute of Industrial Science, The University of Tokyo, 4-6-1 Komaba, Meguro-ku, Tokyo 153-8505, Japan (M. Aziz).

E-mail addresses: arif.d.aa@m.titech.ac.jp (A. Darmawan), maziz@iis.u-tokyo.ac.jp (M. Aziz).
} 

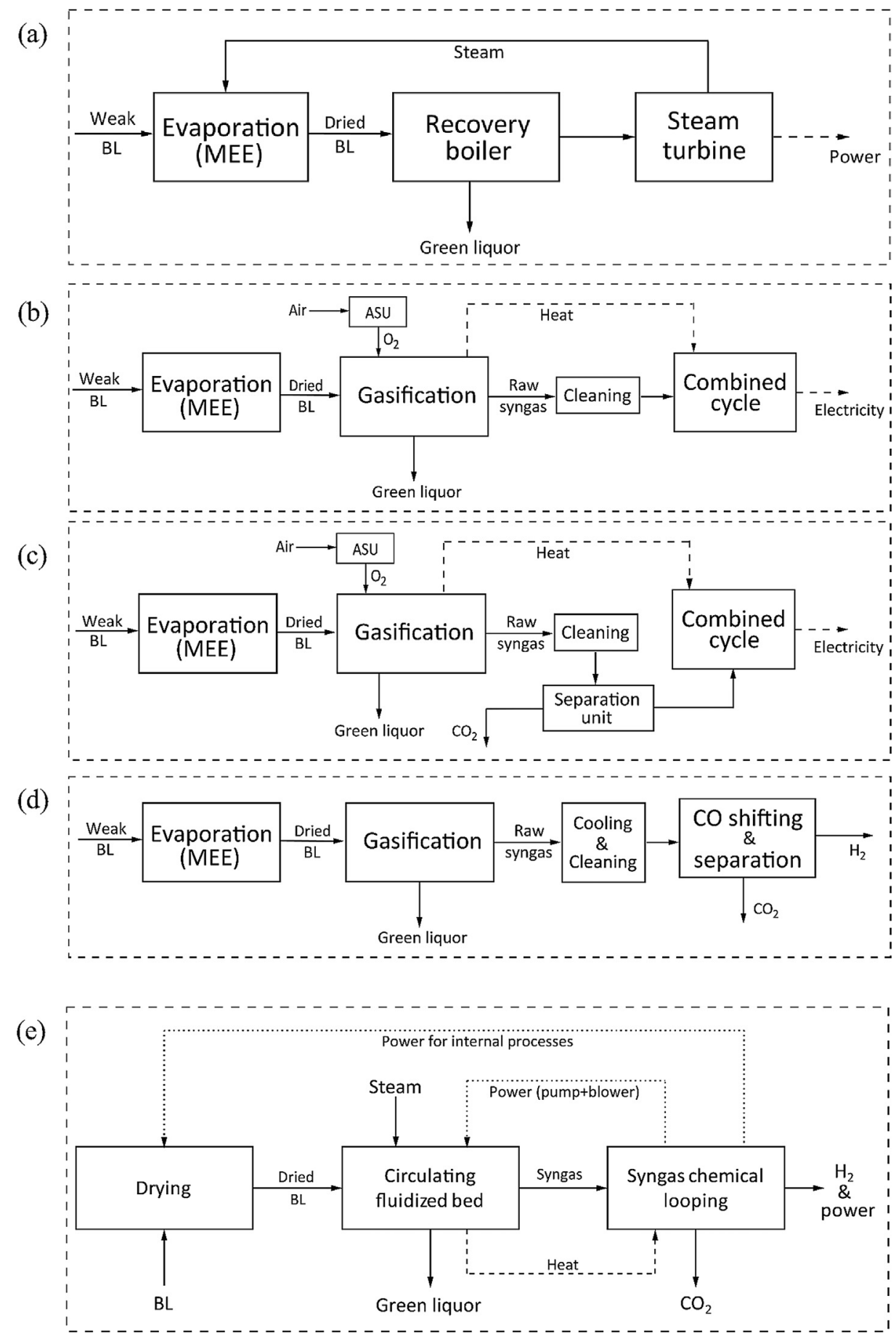

Fig. 1. Conceptual diagrams of the compared systems: (a) MEE + conventional recovery boiler, (b) MEE + BLGCC, (c) MEE + BLGCC with CO 2 capture, (d) MEE + conventional $\mathrm{H}_{2}$ production, and (e) cogeneration of $\mathrm{H}_{2}$ \& power.

high, about $85 \mathrm{wt} \%$ on wet basis, drying becomes a mandatory pretreatment before converting or harvesting energy from weak BL. Unfortunately, since drying is an energy-intensive process, it potentially reduces the total energy efficiency [5]. Therefore, a conversion process that can bypass drying is preferred to achieve high total energy efficiency. Among the gasification technologies, supercritical water gasification (SCWG) has some advantages such as relatively lower operating temperature and no requirement for drying prior to the gasification [6,7]. It is also observed that gasification is a more reliable technology with better results on material decomposition and chemical energy value compared to other processes [8].

Various routes have been proposed to utilize BL on an industrial scale to produce power, biofuel, and heat. Huet at al. [9] performed an experimental study on the SCWG of BL at supercritical conditions of up to $470{ }^{\circ} \mathrm{C}$ and $27 \mathrm{MPa}$. They found that the gas that was produced was mainly a mixture of $\mathrm{H}_{2}, \mathrm{CH}_{4}$, and $\mathrm{CO}_{2}$. In addition, the optimum result could be obtained at a temperature of $470{ }^{\circ} \mathrm{C}$. At this temperature, all the organic carbon could be decomposed. However, their work did not cover any effort on reducing energy loss, which is necessary to circulate and recover the energy throughout the system. Cao et al. [6] studied and investigated $\mathrm{H}_{2}$ production via SCWG, $\mathrm{H}_{2}$ separation employing pressure swing adsorption, and power generation adopting steam turbine. Due to the energy-intensive process during separation, significant energy loss occurred during the process. Moreover, Cao et al. [10] 
studied the effect of BL evaporation on both energy and exergy efficiencies, and found that the total efficiency of the system decreased when BL evaporation was adopted prior to SCWG. Andersson and Harvey [11] reported the performance of the conventional BL gasification system to produce $\mathrm{H}_{2}$ with an emphasize on the $\mathrm{CO}_{2}$ emission. Nonetheless, there was no attempt on improving the investigated system from the perspective of energy efficiency. Darmawan et al. [12] proposed a combined system comprising drying of $\mathrm{BL}$, gasification of dried BL, syngas chemical looping (SCL) for $\mathrm{H}_{2}$ production, and power production. However, their system adopted conventional gasification, and therefore the biomass drying process was required.

Biomass utilization to co-produce $\mathrm{H}_{2}$ and power via chemical looping can be considered as carbon-negative, since biomass is carbon neutral and the $\mathrm{CO}_{2}$ produced from the reducer is separated. After the conversion of BL via gasification, SCL is utilized to efficiently produce $\mathrm{H}_{2}$ and power. Owing to the multiple reactor nature of SCL, $\mathrm{H}_{2}$ and $\mathrm{CO}_{2}$ are produced in different reactors; therefore, the additional step required to separate $\mathrm{CO}_{2}$ could be eliminated. The co-production of $\mathrm{H}_{2}$ and power from syngas is conducted by cyclic treatment of an iron oxide-based looping medium with syngas and steam. The SCL process consists mainly of reduction, oxidation, and combustion in interconnected reactors to produce pure $\mathrm{H}_{2}, \mathrm{CO}_{2}$, and power [13]. Mukherjee et al. found that iron-based OCs are more favorable than other OCs, as they enable higher net electrical efficiency owing to the greater values of their reaction enthalpy during oxidation with air [14].

Through a keyword search in Scopus and Google Scholar, it was found that there is almost no study that emphasizes on the effective SCWG-SCL combination system for $\mathrm{H}_{2}$ production and power generation from biomass, especially BL. Based on this finding, in this study, this combination is proposed and evaluated. The application of SCWG to harvest energy from BL is considered very appropriate, as weak BL having high moisture content can be processed directly without drying. To increase the energy efficiency, the principles of exergy recovery and process integration are applied in this study. This combination method can significantly reduce exergy losses throughout the system. It has been evaluated in several industrial systems, such as biomass-based power generation [15-17], coal-based power generation [18,19], and $\mathrm{H}_{2}$ production [20].

\section{Energy recovery of $\mathrm{BL}$ for $\mathrm{H}_{2}$ and power generation}

As mentioned earlier, a pulp mill industry has a significant energy potential of about 250-500 MW from BL waste [21]. Some existing pulp mills have adopted various methods for energy recovery from BL in order to improve the economic benefit. In this section, various technologies of BL utilization are discussed for comparison with the proposed system in the next section. Fig. 1(a) illustrates the common method of recovery in the existing modern pulp mill industry, which utilizes a boiler to produce steam. Before the combustion process, multiple-effect evaporators (MEE) are employed to remove the water, making it suitable for direct combustion at a solid content of about $70-75 \mathrm{wt} \% \mathrm{wb}$. The heat produced in the combustor is then employed to produce steam at a high pressure and temperature. This steam is then utilized to rotate the turbine and the remaining steam is further distributed for internal processes inside the pulp mill.

Fig. 1(b) and (c) illustrate the simplified model of the BL gasification combined cycle (BLGCC) with and without $\mathrm{CO}_{2}$ capture based on the business-as-usual scheme of the pulp mill industry, respectively $[22,23]$. These integrated systems mainly comprise an air separation unit (ASU), gasification, and gas and steam turbines. Additional cost is needed to install $\mathrm{CO}_{2}$ capture for cleaner power production. BLGCC is considered to have higher efficiency than BL recovery via direct combustion and has the ability to export the surplus power to the grid [21].

Andersson and Harvey [11] proposed and investigated the potential for $\mathrm{H}_{2}$ production via gasification, gas cleaning, and separation (Fig. 1(d)). In this system, 100\% carbon capture is possible after the CO shifting and separation process stage. It offers a cleaner and highly efficient system during operation. The proposed system shown in Fig. 1(e) mainly comprises evaporation of $\mathrm{BL}$, gasification, and the syngas chemical looping (SCL process). The chemical looping process comprises three main reactors: reduction, oxidation, and combustion reactors. In the reduction reactor, the syngas produced from the gasifier reacts with the oxygen carriers (OCs) to form steam and $\mathrm{CO}_{2}$. The OCs leaving the reduction reactor are subsequently introduced into the oxidation reactor, where they react with steam at a temperature range of 500-750 ${ }^{\circ} \mathrm{C}$, generating $\mathrm{H}_{2}$ with unconverted steam. Therefore, pure $\mathrm{H}_{2}$ can be obtained by simply condensing the steam during this step, assuming complete condensation occurs. Afterward, the used OCs are returned to their original state through oxidation in oxidation and combustion reactors. The hot gases generated in each process are recovered by expanding them to generate power.

\section{Methodology}

\subsection{Exergy recovery and process integration technologies}

A high energy efficiency can be achieved in the system by performing the combination of process integration and exergy recovery. The basic idea of the approach is to utilize exergy recovery in each process before being integrated with the other processes. This idea is substantially different from that of conventional process integration, in which less attention is paid to the quality of the recovered heat stream, which results in smaller amounts of energy being recovered [15]. Fig. 2 shows the process of exergy recovery and the effort to elevate the exergy rate by compression and heat combination [2].

Through exergy rate elevation, a hot stream or exergy-elevated stream can be created from its own process (process stream), and therefore, the possibility of effective heat pairing is obtained. This method can realize self-heat exchange and minimize exergy destruction.

Process integration is additionally employed to effectively combine the involved modules, as well as efficiently utilize the heat that cannot be recovered anymore from each single module to the other modules. This leads to a more optimized system and a larger amount of heat that

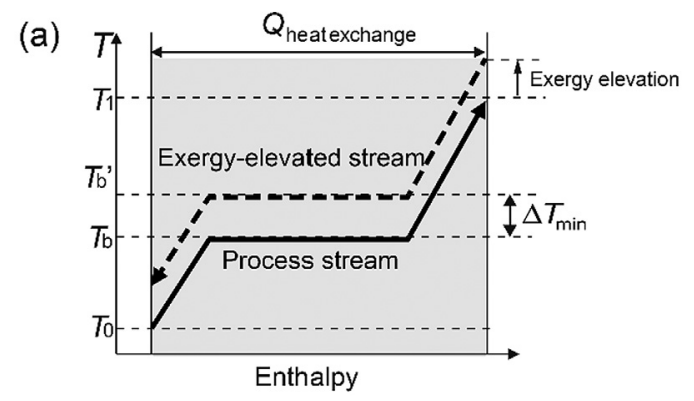

(b)

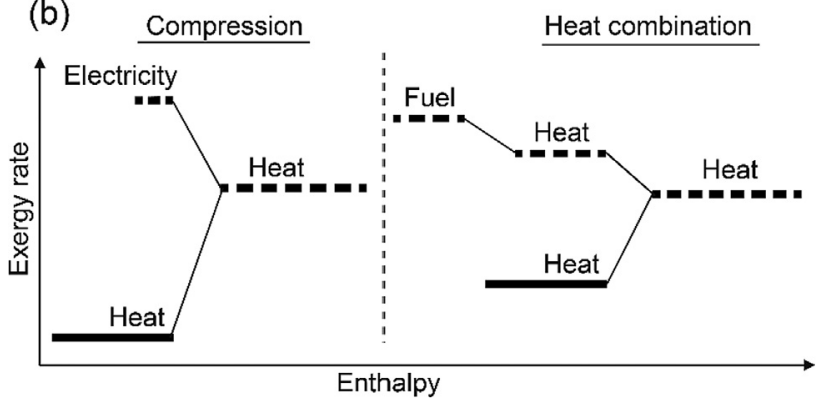

Fig. 2. Exergy recovery principle: (a) exergy elevation of the stream and heat coupling between the hot stream and process streams, (b) exergy rate elevation through compression and heat combination [2]. 


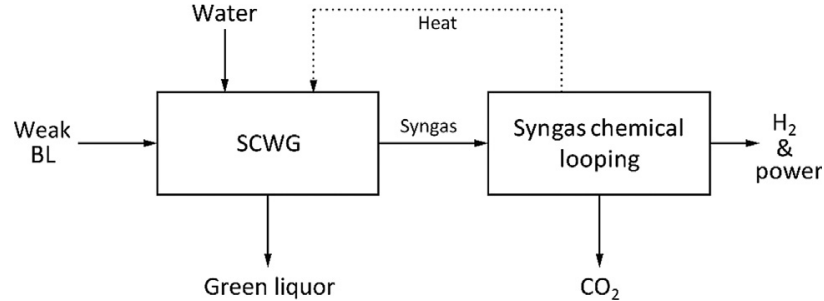

Fig. 3. Schematic diagram of SCWG of BL and syngas chemical looping for coproducing power and $\mathrm{H}_{2}$.

can be recovered. Hence, minimization of exergy destruction throughout the integrated system can be achieved, resulting in excellent total energy efficiency. This method has already been studied before and could significantly reduce the exergy losses $[19,24]$. It has been evaluated in many types of systems, such as power generation from biomasses $[16,17]$, fossil-based power generation $[18,25], \mathrm{H}_{2}$ production $[12,15]$, and combined integrated system [26].

\subsection{Proposed integrated system}

Fig. 3 shows the schematic process flow diagram of the developed system, which combines SCWG and syngas chemical looping for BL. The hot mixture of syngas and steam produced from the gasifier is superheated to increase its exergy rate to achieve a self-heat exchange, in which this hot mixture becomes the heat source providing the heat required for gasification. Consecutively, the mixture of syngas and steam also flows to the preheaters to preheat both $\mathrm{BL}$ and water for fluidization before being condensed for separating syngas from water.

The SCL process mainly comprises three main stages: reduction, oxidation, and combustion. In the reducer, syngas is reacted with OCs to form $\mathrm{CO}_{2}$ and steam. The OCs leaving the reduction stage are subsequently introduced into the oxidizer and reacted with steam, generating $\mathrm{H}_{2}$ with unconverted steam. Therefore, pure $\mathrm{H}_{2}$ can be obtained by simply condensing the steam during this step, assuming complete condensation occurs. Afterward, the used OCs are returned to their original state by combustion with air. The hot gas generated in each process is recovered by expanding it to generate power.

\subsection{General condition}

In this study, Aspen Plus version 8.8 process simulator is used to perform process modeling and thermodynamic simulations of the developed system. Considering the current average pulp production in an actual industry, the BL flow rate entering the evaporation process is fixed at $348.12 \mathrm{th}^{-1}$. For process modeling, a few assumptions are made: (i) All the heat exchangers in the system have a minimum difference temperature of $10^{\circ} \mathrm{C}$; (ii) the atmospheric temperature is set to $25^{\circ} \mathrm{C}$; (iii) the blower and compressor have an adiabatic efficiency of $90 \%$. Moreover, the air consists of $\mathrm{N}_{2}$ and $\mathrm{O}_{2}$ with fractions of 79 and $21 \mathrm{~mol} . \%$, respectively. The BL used in the simulation has the composition described in [12].

\subsection{Detailed process}

Fig. 4 shows the detailed flow diagram of the proposed integrated system for energy-efficient coproduction of power and $\mathrm{H}_{2}$ from BL. The parameters used during SCWG are shown in Table 1. Because of its excellent characteristics such as no requirement for drying and capability to produce $\mathrm{H}_{2}$-rich syngas, SCWG is considered as the main process for conversion. Weak BL with a high moisture content is initially fed to the SCWG reactor and water is pumped and utilized as the reactant. It should be noted that the slurry (weak BL) is pumped to the target pressure for SCWG (higher than $22 \mathrm{MPa}$ ) before it is preheated (HX1 and HX3) and flowed to the SCWG reactor.
A fluidized bed is adopted as the SCWG reactor due to its characteristics such as ability to prevent plugging, high gasification efficiency, and continuous syngas production with high conversion rate [27]. Silica sand is inserted as fluidizing particles inside the reactor for better heat transfer and temperature distribution across the reactor. In addition, water is used as the fluidization medium, and it is fed from the bottom of the bed. The pressure drop and the minimum bubbling velocity across the fluidized bed are approximated with the following formulas [28]:

$\frac{\Delta_{p}}{L}=150 \frac{(1-\varepsilon)^{2}}{\varepsilon^{3}} \times \frac{\mu_{f} U_{f}}{\varphi_{p} d_{p}}+1.75 \frac{1-\varepsilon}{\varepsilon^{3}} \times \frac{\rho_{f} U_{f}^{2}}{\varphi_{p} d_{p}}$

where $L, \varepsilon, \mu$, and $U$ are the fluidization height, voidage, viscosity, and superficial fluid velocity, respectively. In addition, $\varphi$, $d$, and $\rho$ represent the sphericity, average diameter, and density of the used fluidizing particles, respectively. Furthermore, the subscripts $f$ and $p$ represent the fluidization medium and particle, respectively. The minimum bubbling velocity, $U_{\mathrm{mb}}$, is calculated based on the study of Wei and Lu [28] for fluidization of supercritical water:

$U_{m b}=\frac{R e_{m b} \times \mu_{f}}{\rho_{f} \times d_{p}}$

$R e_{m b}=2 \times 10^{-8} A r^{2}-9 \times 10^{-8} A r+1.4608$

$A r=\frac{d_{p}^{3} \times \rho_{g} \times\left(\rho_{p}-\rho_{f}\right) \times g}{\mu_{f}^{2}}$

where $A r$ and $g$ are the Archimedes number and acceleration due to gravity, respectively.

In addition, heat exchanger tubes are installed inside the gasifier. Under supercritical condition, the density of water and hydrogen bond decreases significantly. As a result, water behaves as a non-polar solvent; hence, the reaction can be conducted under homogeneous condition [29].

In the ASPEN Plus process simulator, the gasification process and superheating process are modelled using the RGibbs reactor along with heat exchangers. The main goal of the simulation is to evaluate the heating needed to support the SCWG process. The syngas output is taken from another experimental study by Sricharoenchaikul [30]. The overall exergy balance for the SCWG described here can be written as

$\dot{E}_{B L}+\dot{E}_{\text {water }}+\dot{W}_{\text {el }}=\dot{E}_{\text {gas }}+\dot{E}_{\text {wasteheat }}+\dot{I}_{\text {overall }}$

where $\dot{E}_{B L}$ and $\dot{E}_{\text {water }}$ are the exergy rates of the BL and fluidizing water, respectively, $\dot{W}_{e l}$ represents the electric power supply, $\dot{E}_{g a s}$ is the exergy rate of the produced gas, $\dot{E}_{\text {wasteheat }}$ is the external exergy loss from the condenser (unrecovered heat), and $\dot{I}_{\text {overall }}$ represents the overall internal exergy loss in the system (irreversibility rate). Since SCWG is a complicated process consisting of many chemical reactions, there are basically two main reactions during gas production [31] as follows:

$\mathrm{CH}_{x} \mathrm{O}_{y}+(2-\mathrm{y}) \mathrm{H}_{2} \mathrm{O} \rightarrow \mathrm{CO}_{2}+(2-y+0.5 \mathrm{x}) \mathrm{H}_{2}$

$\mathrm{CH}_{x} \mathrm{O}_{y}+(1-\mathrm{y}) \mathrm{H}_{2} \mathrm{O} \rightarrow \mathrm{CO}+(2-y+0.5 \mathrm{x}) \mathrm{H}_{2}$

where $\mathrm{x}$ and $\mathrm{y}$ are the $\mathrm{H} / \mathrm{C}$ and $\mathrm{O} / \mathrm{C}$ molar ratios of the processed BL, respectively. Subsequently, the hot mixture of the produced syngas and steam exhausted out from the top of the SCWG reactor is superheated (HX5) to elevate its exergy rate before being returned back and utilized as the heat source for subsequent SCWG and preheating. In the SCL process, pure $\mathrm{H}_{2}$ and concentrated $\mathrm{CO}_{2}$ can be produced in two separated reactors based on the cyclic reduction and oxidation processes. The SCL process mainly consists of three interconnected reactors, namely reducer, oxidizer, and combustor, as shown conceptually in Fig. 5. In ASPEN Plus, these processes are modeled using the RStoic reactor model.

Based on the pilot-scale SCL plant currently under operation [13], in 


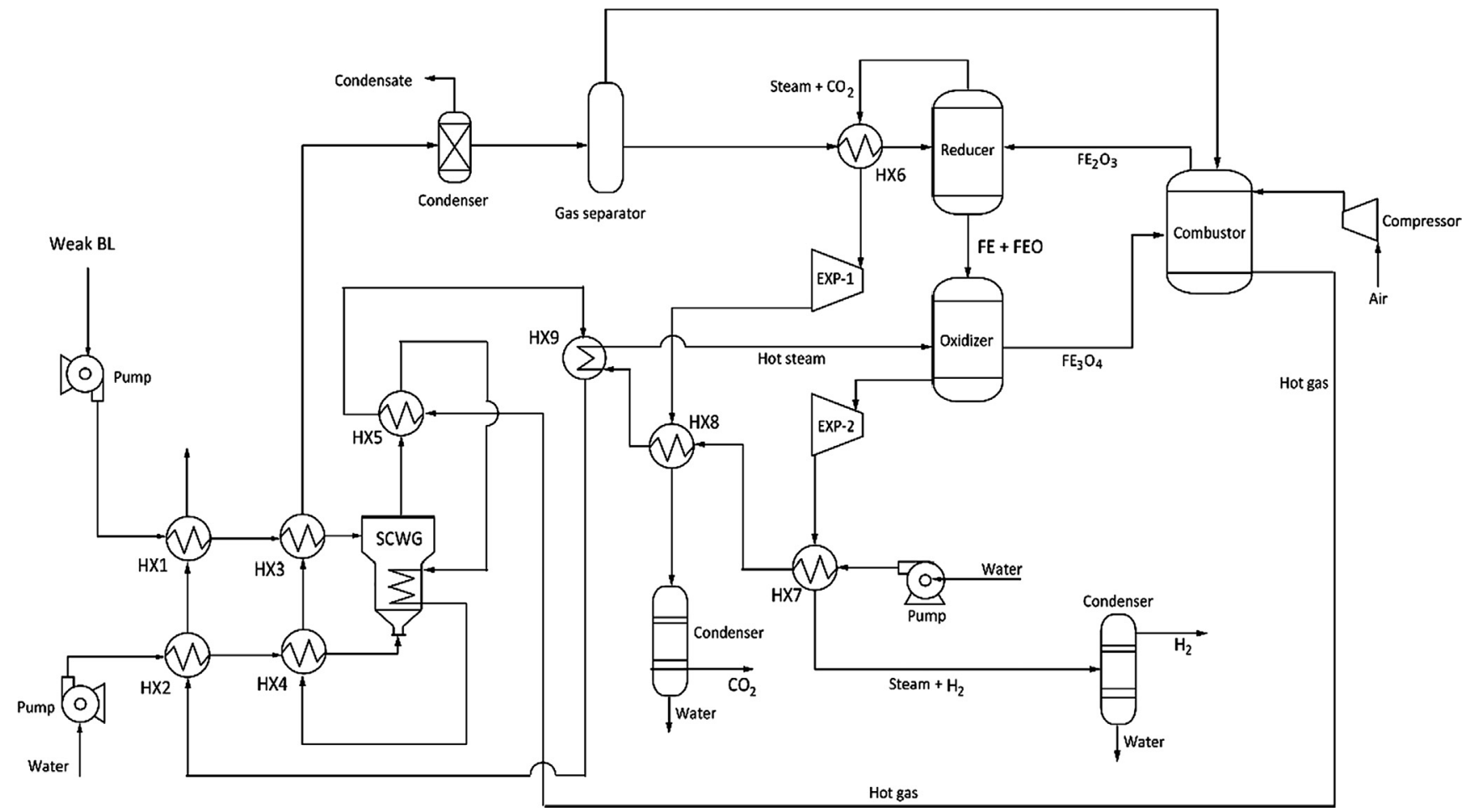

Fig. 4. Schematic diagram of the SCWG of BL, SCL, and power generation.

Table 1

Main conditions during SCWG [30].

\begin{tabular}{ll}
\hline Specification & Value \\
\hline Gasification temperature $\left({ }^{\circ} \mathrm{C}\right)$ & 375,500, and 650 \\
Pressure condition $(\mathrm{MPa})$ & 40 \\
Type of gasification & Supercritical water gasification \\
Flow rate of solid $\mathrm{BL}\left(\mathrm{t} \mathrm{h}^{-1}\right)$ & 50.4 \\
Water content $(\%)$ & 90
\end{tabular}

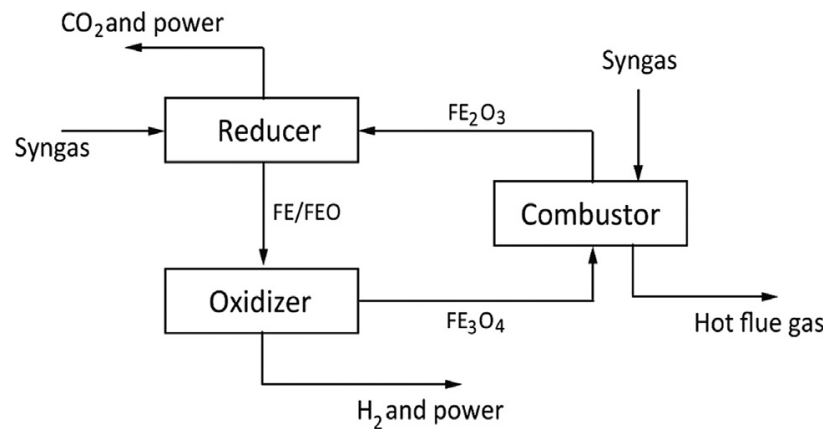

Fig. 5. . Conceptual diagram of SCL stage.

this study, the reducer and oxidizer use a counter-current moving bed reactor, while an entrained bed is adopted for the combustor. For the OCs, an iron-based material is used to facilitate multiple reactions during the process. The solid mass fraction, which is employed in the SCL process, is set to $70 \% \mathrm{Fe}_{2} \mathrm{O}_{3}, 15 \% \mathrm{SiC}$, and $15 \% \mathrm{Al}_{2} \mathrm{O}_{3}$. Based on the experimental investigation, the equilibrium gas concentration is also considered during the calculations in this study [13].

A higher pressure leads to optimum gas-solid conversion and also a smaller reactor size due to the higher kinetics condition [13,32]. A high temperature of up to $900{ }^{\circ} \mathrm{C}$ is suggested to achieve the best performance and better efficiency during the reduction process; therefore, the syngas can be completely converted into $\mathrm{CO}_{2}$ and steam [13].
Moreover, the heat from the steam and the $\mathrm{CO}_{2}$ exhausted from the reduction reactor are recovered for preheating the water (HX-8); afterwards, it is expanded in EXP-1 to produce power. The reactions that happen during the reduction process are as follows:

$$
\begin{aligned}
& \mathrm{Fe}_{2} \mathrm{O}_{3}+\mathrm{H}_{2} \rightarrow 2 \mathrm{FeO}+\mathrm{H}_{2} \mathrm{O} \quad \Delta \mathrm{H}=38.4 \mathrm{~kJ} \mathrm{~mol}^{-1} \\
& \mathrm{Fe}_{2} \mathrm{O}_{3}+\mathrm{CO} \rightarrow 2 \mathrm{FeO}+\mathrm{CO}_{2} \quad \Delta \mathrm{H}=-2.8 \mathrm{~kJ} \mathrm{~mol}^{-1} \\
& \mathrm{FeO}+\mathrm{H}_{2} \rightarrow \mathrm{Fe}+\mathrm{H}_{2} \mathrm{O} \quad \Delta \mathrm{H}=30.2 \mathrm{~kJ} \mathrm{~mol}^{-1} \\
& \mathrm{FeO}+\mathrm{CO} \rightarrow \mathrm{Fe}+\mathrm{CO}_{2} \quad \Delta \mathrm{H}=-11 \mathrm{~kJ} \mathrm{~mol}^{-1} \\
& 4 \mathrm{Fe}_{2} \mathrm{O}_{3}+3 \mathrm{CH}_{4} \rightarrow 8 \mathrm{Fe}+3 \mathrm{CO}_{2}+6 \mathrm{H}_{2} \mathrm{O} \quad \Delta \mathrm{H}=897.175 \mathrm{~kJ} \mathrm{~mol}^{-1}
\end{aligned}
$$

For the oxidation process, the reduced OCs react with steam, generating $\mathrm{H}_{2}$, which flows out together with the excess steam. The stream containing high-pressure steam and $\mathrm{H}_{2}$ exiting the oxidizer is utilized to generate power through expansion in EXP-2. High purity $\mathrm{H}_{2}$ can be obtained fully once the steam is condensed. The oxidation reactions are as follows:

$$
\begin{aligned}
& \mathrm{Fe}+\mathrm{H}_{2} \mathrm{O}(\mathrm{g}) \rightarrow \mathrm{FeO}+\mathrm{H}_{2}(\mathrm{~g}) \quad \Delta \mathrm{H}=-30.2 \mathrm{~kJ} \mathrm{~mol}^{-1} \\
& 3 \mathrm{FeO}+\mathrm{H}_{2} \mathrm{O}(\mathrm{g}) \rightarrow \mathrm{Fe}_{3} \mathrm{O}_{4}+\mathrm{H}_{2} \quad \Delta \mathrm{H}=-60.6 \mathrm{~kJ} \mathrm{~mol}^{-1}
\end{aligned}
$$

The $\mathrm{Fe}_{3} \mathrm{O}_{4}$ generated in the oxidizer is reacted with $\mathrm{O}_{2}$ in the combustor; therefore, it is recycled back into $\mathrm{Fe}_{2} \mathrm{O}_{3}$. A certain amount of syngas is also added to the combustor and reacted with $\mathrm{O}_{2}$ to satisfy the heat requirement during the SCL process. This reaction can provide more heat to support the overall SCL process. Furthermore, the heat brought by the hot exhaust gas from the combustor is used to elevate the exergy rate of the air inlet stream, while the remaining energy (heat and pressure) is recovered using the expander for power generation (EXP-3). Notably, the pressure in the combustor is $0.2 \mathrm{MPa}$ higher than that in both reducer and oxidizer, as suggested in other studies [2,19]. The reactions involved here are as follows:

$$
4 \mathrm{Fe}_{3} \mathrm{O}_{4}+\mathrm{O}_{2} \rightarrow 6 \mathrm{Fe}_{2} \mathrm{O}_{3} \quad \Delta \mathrm{H}=-471.6 \mathrm{~kJ} \mathrm{~mol}^{-1}
$$$$
2 \mathrm{H}_{2}+\mathrm{O}_{2} \rightarrow 2 \mathrm{H}_{2} \mathrm{O} \quad \Delta \mathrm{H}=-457 \mathrm{~kJ} \mathrm{~mol}^{-1}
$$ 
Table 2

Assumed operating conditions during SCL process.

\begin{tabular}{ll}
\hline Parameters & Value \\
\hline Minimum temperature during reduction $\left({ }^{\circ} \mathrm{C}\right)$ & 900 \\
Minimum temperature during oxidation $\left({ }^{\circ} \mathrm{C}\right)$ & 820 \\
Minimum combustion temperature $\left({ }^{\circ} \mathrm{C}\right)$ & 1100 \\
Pressure condition $(\mathrm{MPa})$ & $2-3.5$ \\
Isentropic efficiency of compressors $(\%)$ & 90 \\
Efficiency of pumps $(\%)$ & 90 \\
Mass fraction of solid material & $70 \% \mathrm{Fe}_{2} \mathrm{O}_{3}, 15 \% \mathrm{Al}_{2} \mathrm{O}_{3}, 15 \% \mathrm{SiC}$ \\
Oxidation and reduction reactor & Counter-current moving bed \\
Combustion reactor & Entrained bed \\
\hline
\end{tabular}

The details of the conditions during the SCL stage are listed in Table 2 below.

\subsection{Performance evaluation}

The calculation to evaluate the total efficiency of the proposed system is shown in Eq. (17) below:

$\eta_{\text {net }}=\frac{P_{\text {output }}-P_{\text {internal }}}{P_{\text {input }}}$

where $P_{\text {output }}, P_{\text {internal }}$, and $P_{\text {input }}$ are the sum of the produced $\mathrm{H}_{2}$ and power, power consumed by the system, and total energy input (BL (MW) and external power), respectively. The internal power consumption of the system include the power consumed for various functions of the pump before the SCWG and the power consumed by the compressors and pumps in SCL. In this study, the developed system is examined under several conditions of SCWG and operating pressures of the SCL reactors to evaluate the performance of the system in terms of energy efficiency.

\section{Results and discussion}

\subsection{Performance of different integrated systems}

The performance comparison of different integrated systems for BL utilization, in terms of the LHV-based efficiency, is listed in Table 3. The integrated systems mostly adopt drying as the pretreatment for weak BL. The drying or evaporation systems increase the solid content of BL up to $70 \mathrm{wt} \% \mathrm{wb}$ or higher, before it is combusted or gasified. Among the listed systems, the developed system, which combines the SCWG and SCL processes, has the highest energy efficiency of $82 \%$ (LHVbased), with $75 \%$ carbon capture. The combination of process integration and heat recovery can produce heat and $\mathrm{H}_{2}$ simultaneously, as well as effectively separate the $\mathrm{CO}_{2}$ by reduction through SCL and condensation. Since a small part of the syngas is also allocated for the combustion process in SCL, complete $\mathrm{CO}_{2}$ capture cannot be achieved. Furthermore, as supercritical conditions lead to a significant drop in the water density and hydrogen bond, gasification can be conducted in relatively lower temperatures, but with high energy efficiency. Another advantage of the combination of SCWG and SCL processes is that the

Table 3

Performance comparison of several combined systems for BL utilization.

\begin{tabular}{lllll}
\hline & $\begin{array}{l}\mathrm{H}_{2} \\
(\% \\
\mathrm{LHV})\end{array}$ & $\begin{array}{l}\mathrm{CO}_{2} \\
\text { capture } \\
(\%)\end{array}$ & $\begin{array}{l}\text { Net } \\
\text { power } \\
(\% \mathrm{LHV})\end{array}$ & $\begin{array}{l}\text { Efficiency } \\
\text { (\%LHV) }\end{array}$ \\
\hline MEE + Conventional recovery boiler & - & - & $9-14$ & $9-14$ \\
MEE + BLGCC & - & - & 24 & 24 \\
MEE + BLGCC with $\mathrm{CO}_{2}$ capture & - & 90 & 22.4 & 22.4 \\
MEE + conventional $\mathrm{H}_{2}$ production & 37.5 & 90 & - & 37.5 \\
Drying + Gasification + SCL process & 64.4 & 99.99 & 4.7 & 69.1 \\
SCWG + SCL process & $\mathbf{8 7 \%}$ & $\mathbf{7 5}$ & - & $\mathbf{8 2 \%}$ \\
\hline
\end{tabular}

produced syngas has a high pressure, thus avoiding further compression, which requires high energy.

A conventional BL recovery system generally utilizes a conventional recovery boiler leading to a lower energy efficiency. After the MEE process, BL having low water content is fed to the boiler for direct combustion. The MEE process also uses the steam generated from this combustion. Compared to conventional drying, MEE has higher efficiency as it adopts several reactors, which results in higher cost for installation. In addition, the system also results in a relatively high energy loss as it employs a conventional back-pressure/extraction steam turbine cycle. In contrast, a higher energy efficiency of $24 \%$, about double that of the conventional system, can be achieved by adopting BLGCC. In addition, the syngas combustion can produce a larger amount of electricity through the gas turbine. Furthermore, the still-high temperature exhaust gas from the gas turbine can be utilized to produce steam having high pressure and temperature, which will be expanded in the back-pressure steam turbine cogeneration system.

MEE + BLGCC with $\mathrm{CO}_{2}$ capture potentially consumes larger amounts of energy to separate $\mathrm{CO}_{2}$, resulting in a lower efficiency of $22.4 \%$. The next system, conventional $\mathrm{H}_{2}$ production, employs the water-gas shift reaction to generate $\mathrm{H}_{2}$ and $\mathrm{CO}_{2}$. However, similar to MEE, this water-gas shift process also consumes a very large amount of energy. The systems in which MEE is adopted generally consume a large amount of power for the auxiliaries and a large amount of heat for steam production.

The integrated system comprising drying, gasification, and SCL process has a relatively high total LHV-based energy efficiency, which is about $69 \%$. By adopting exergy recovery and process integration, the combined system can yield a high efficiency for $\mathrm{H}_{2}$ and power co-production. The $\mathrm{CO}_{2}$ separation can also be performed during the SCL process, thereby avoiding additional energy penalty for $\mathrm{CO}_{2}$ separation. Unfortunately, additional cost and power are required for the drying process prior to gasification, which is performed to remove the high water content in the BL.

\subsection{Performance of proposed system}

The effect of gasification temperature on the gas produced during the SCWG process and the total $\mathrm{H}_{2}$ produced is shown in Fig. 6. The result shows that the SCWG conducted at $650{ }^{\circ} \mathrm{C}$ resulted in the highest $\mathrm{H}_{2}$ production, which is $4.13 \mathrm{th}^{-1}$. Increasing the SCWG temperature generally results in increased $\mathrm{H}_{2}$ production during the SCL process. In addition, although the $\mathrm{H}_{2}$ mass concentration of the gas produced during gasification is lower at a higher gasification temperature, the amount of $\mathrm{H}_{2}$ is still higher than that at a lower temperature. After gasification, $\mathrm{CO}, \mathrm{CH}_{4}$, and $\mathrm{C}_{2} \mathrm{H}_{6}$ are oxidized, thus producing $\mathrm{CO}_{2}$, while the OCs are reduced to $\mathrm{Fe}$ and $\mathrm{FeO}$. Therefore, a higher calorific value of the syngas produced from gasification is beneficial in terms of the total energy efficiency.

Since the syngas composition is assumed based on a lab scale experimental study, it is important to clarify that a pilot scale experiment is needed to verify it in a real application. In addition to clarifying the gas output during SCWG, the pilot-scale research can also observe the fluidization behavior under high pressure, such as the pressure drop and the minimum bubbling velocity across the fluidized bed reactor.

The effects of temperature during SCWG on the SCL performance such as the amount of $\mathrm{H}_{2}$ generated, amount of $\mathrm{CO}_{2}$ captured, and overall system efficiency are shown in Fig. 7. The system efficiency is considerably increased at higher temperature. The result shows that the SCWG conducted at $650^{\circ} \mathrm{C}$ resulted in the highest system efficiency, which is about $80 \%$. The amount of $\mathrm{CO}_{2}$ captured increased from about $11 \mathrm{th}^{-1}$ to $28.35 \mathrm{th}^{-1}$ when the SCWG temperature was shifted from 375 to $650{ }^{\circ} \mathrm{C}$. The $\mathrm{CO}_{2}$ captured corresponds to the $\mathrm{CO}_{2}$ capture efficiency of $75 \%$. The remaining $\mathrm{CO}_{2}$ is released to the environment during syngas combustion in the combustor to provide the required heat during the SCL process. 


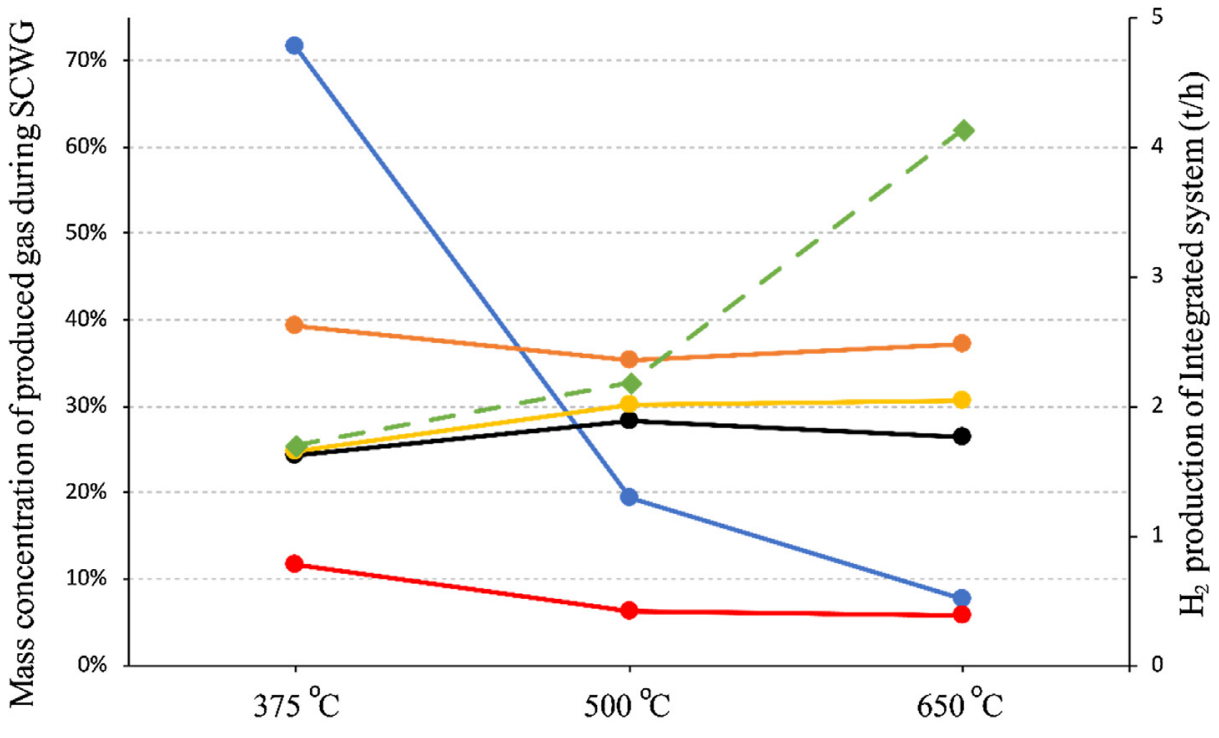

Temperature of SCWG

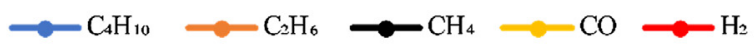

$-\mathrm{H}_{2}$ production $(\mathrm{t} / \mathrm{h})$

Fig. 6. . The effect of temperature during SCWG on the mass concentration of the produced gas and the $\mathrm{H}_{2}$ generated during SCL.

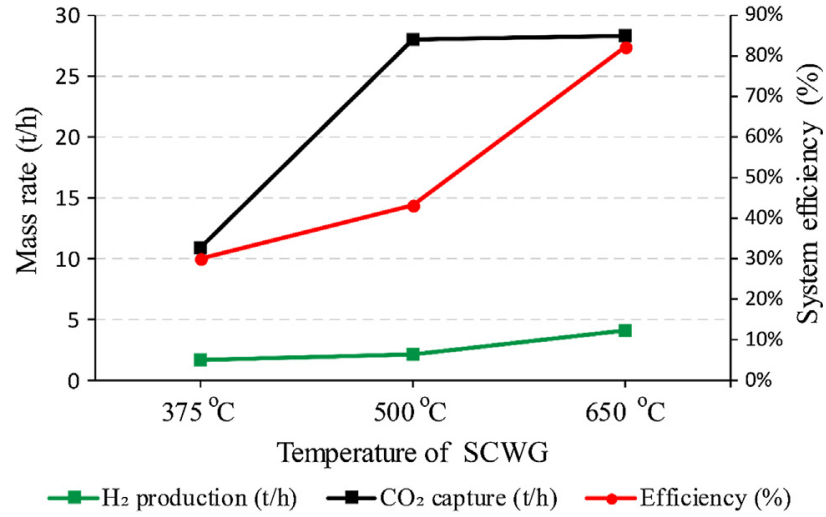

Fig. 7. . Correlation of temperature during gasification with SCL performance.
Fig. 8 shows the performance of the developed system under different SCL pressures. In order to clearly evaluate the impact of the SCL operating pressure, the flow rate of metal $\left(\mathrm{Fe}_{2} \mathrm{O}_{3}+\right.$ inert) in the SCL process, temperature, and gasification pressure are kept constant at $80 \mathrm{~kg} / \mathrm{s}, 650^{\circ} \mathrm{C}$, and $40 \mathrm{MPa}$, respectively. It is found that there is no significant change in the total net energy efficiency under different SCL operating pressures. However, the net power decreases slightly following the increase in SCL pressure, due to the higher power consumed by the compressors and pumps during the SCL process.

During further investigation of the continuous system, it is important to consider some factors that can affect the overall efficiency in order to avoid misleading results. The operational difficulty of moving solids is not discussed in detail in this research. Since the handling of solids is a cumbersome process, it becomes crucial to investigate possible energy losses that occur during a continuous process.

\section{Conclusion}

A combined system for converting BL to $\mathrm{H}_{2}$ has been developed

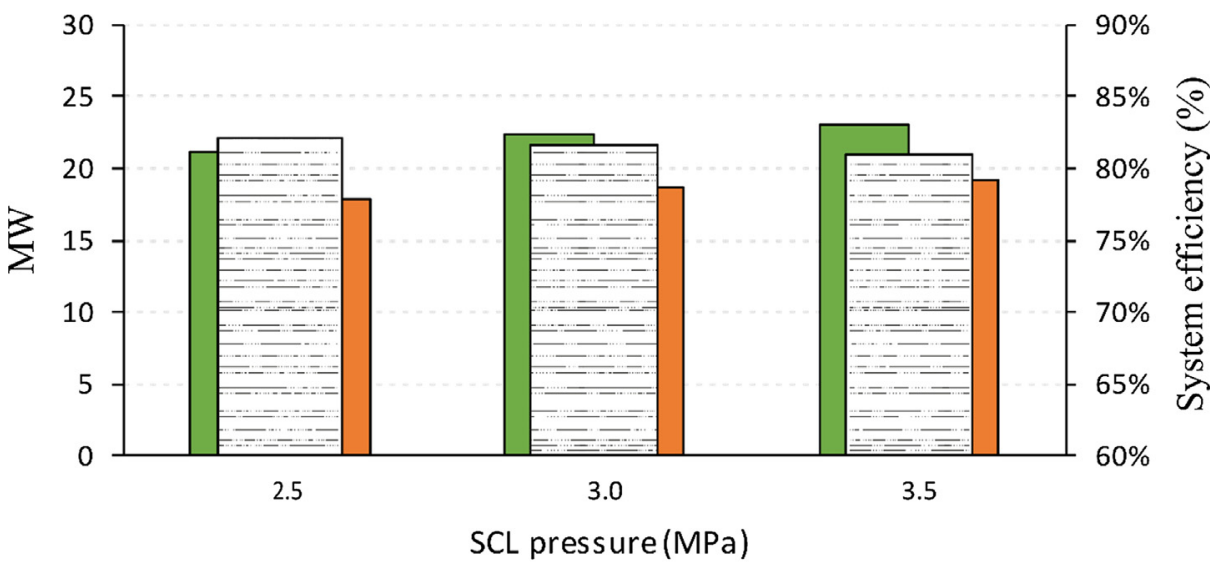

$\square$ Internal power consumption (MW) $\square$ Power produced (MW) $\square$ System efficiency (\%)

Fig. 8. . Impacts of SCL operating pressure on the system performance. 
using energy-recovery and process integration technologies. The developed system, which mainly consists of the SCWG and SCL processes, can achieve a very high total net energy efficiency of about $80 \%$. Compared to other recovery systems for BL, the developed system appears very promising. In the developed system, it is not necessary to remove the water content beforehand. In addition, $75 \%$ of the concentrated $\mathrm{CO}_{2}$ stream can be directly condensed after the oxidation process in the SCL stage, thus avoiding the energy requirements for $\mathrm{CO}_{2}$ separation. The combination of the SCWG and SCL processes, with additional adoption of the exergy-recovery and process integration technologies, leads to a highly-efficient and environmentally-clean BL utilization system.

\section{Acknowledgments}

The authors would like to acknowledge the financial support from The Indonesia Endowment Fund for Education (LPDP). In addition, the research was also partly supported by JSPS KAKENHI No. 19 K04211.

\section{References}

[1] Kumar S. Clean hydrogen production methods, vol. 2; 2015. doi:10.1007/978-3319-14087-2.

[2] Aziz M, Juangsa FB, Kurniawan W, Budiman BA. Clean co-production of H2 and power from low rank coal. Energy 2016;116:489-97. https://doi.org/10.1016/j. energy.2016.09.135.

[3] Krejci MC, Mathieu O, Vissotski AJ, Ravi S, Sikes TG, Petersen EL, et al. Laminar flame speed and ignition delay time data for the kinetic modeling of hydrogen and syngas fuel blends. J Eng Gas Turbines Power 2013;135:021503. https://doi.org/ $10.1115 / 1.4007737$

[4] Roy Ghatak H. Electrolysis of black liquor for hydrogen production: some initial findings. Int J Hydrogen Energy 2006;31:934-8. https://doi.org/10.1016/J. IJHYDENE.2005.07.013.

[5] Aziz M, Oda T, Kashiwagi T. Energy-efficient low rank coal drying based on enhanced vapor recompression technology. Dry Technol 2014;32:1621-31. https:// doi.org/10.1080/07373937.2014.915219.

[6] Cao C, Guo L, Jin H, Cao W, Jia Y, Yao X. System analysis of pulping process coupled with supercritical water gasification of black liquor for combined hydrogen, heat and power production. Energy 2017;132:238-47. https://doi.org/10.1016/J. ENERGY.2017.05.104.

[7] Chiang KY, Lin YX, Lu CH, Chien KL, Lin MH, Wu CC, et al. Gasification of rice straw in an updraft gasifier using water purification sludge containing $\mathrm{Fe} / \mathrm{Mn}$ as a catalyst. Int J Hydrogen Energy 2013;38:12318-24. https://doi.org/10.1016/j. ijhydene.2013.07.041.

[8] Ahmed I, Gupta AK. Syngas yield during pyrolysis and steam gasification of paper. Appl Energy 2009;86:1813-21. https://doi.org/10.1016/j.apenergy.2009.01.025.

[9] Huet M, Roubaud A, Lachenal D. Conversion of sulfur-free black liquor into fuel gas by supercritical water gasification. Holzforschung 2015;69:751-60. https://doi. org/10.1515/hf-2014-0254.

[10] Cao C, He Y, Chen J, Cao W, Jin H. Evaluation of effect of evaporation on supercritical water gasification of black liquor by energy and exergy analysis. Int $\mathrm{J}$ Hydrogen Energy 2018;43:13788-97. https://doi.org/10.1016/J.IJHYDENE.2017. 11.158.

[11] Andersson E, Harvey S. System analysis of hydrogen production from gasified black liquor. Energy 2006;31:3426-34. https://doi.org/10.1016/j.energy.2006.03.015.

[12] Darmawan A, Ajiwibowo MW, Yoshikawa K, Aziz M, Tokimatsu K. Energy-efficient recovery of black liquor through gasification and syngas chemical looping. Appl
Energy 2018;219:290-8. https://doi.org/10.1016/j.apenergy.2018.03.033.

[13] Fan L. Chemical looping system for fossil energy conversions 2010:143-214.

[14] Mukherjee S, Kumar P, Yang A, Fennell P. A systematic investigation of the performance of copper-, cobalt-, iron-, manganese- and nickel-based oxygen carriers for chemical looping combustion technology through simulation models. Chem Eng Sci 2015;130:79-91. https://doi.org/10.1016/J.CES.2015.03.009.

[15] Zaini IN, Nurdiawati A, Aziz M. Cogeneration of power and H2 by steam gasification and syngas chemical looping of macroalgae. Appl Energy 2017. https://doi. org/10.1016/j.apenergy.2017.06.071.

[16] Darmawan A, Hardi F, Yoshikawa K, Aziz M, Tokimatsu K. Enhanced process integration of black liquor evaporation, gasification, and combined cycle. Appl Energy 2017;204:1035-42. https://doi.org/10.1016/j.apenergy.2017.05.058.

[17] Prabowo B, Aziz M, Umeki K, Susanto H, Yan M, Yoshikawa K. CO2-recycling biomass gasification system for highly efficient and carbon-negative power generation. Appl Energy 2015;158:97-106. https://doi.org/10.1016/j.apenergy.2015. 08.060 .

[18] Darmawan A, Budianto D, Aziz M, Tokimatsu K. Retrofitting existing coal power plants through cofiring with hydrothermally treated empty fruit bunch and a novel integrated system. Appl Energy 2017. https://doi.org/10.1016/j.apenergy.2017. 03.122.

[19] Aziz M, Zaini IN, Oda T, Morihara A, Kashiwagi T. Energy conservative brown coal conversion to hydrogen and power based on enhanced process integration: Integrated drying, coal direct chemical looping, combined cycle and hydrogenation. Int J Hydrogen Energy 2017;42:2904-13. https://doi.org/10.1016/j.ijhydene. 2016.10.060.

[20] Aziz M. Integrated hydrogen production and power generation from microalgae. Int J Hydrogen Energy 2016;41:104-12. https://doi.org/10.1016/J.IJHYDENE.2015. 10.115.

[21] Naqvi M, Yan J, Dahlquist E. Black liquor gasification integrated in pulp and paper mills: a critical review. Bioresour Technol 2010;101:8001-15. https://doi.org/10. 1016/j.biortech.2010.05.013.

[22] de F Ferreira ET, Balestieri JAP. Black liquor gasification combined cycle with $\mathrm{CO} 2$ capture - technical and economic analysis. Appl Therm Eng 2015;75:371-83. https://doi.org/10.1016/j.applthermaleng.2014.09.026.

[23] Harvey LDD. Carbon-free energy supply; 2010.

[24] Aziz M, Oda T, Kashiwagi T. Enhanced high energy efficient steam drying of algae. Appl Energy 2013;109:163-70. https://doi.org/10.1016/j.apenergy.2013.04.004.

[25] Darmawan A, Budianto D, Aziz M, Tokimatsu K. Hydrothermally-treated empty fruit bunch cofiring in coal power plants: a techno-economic assessment. Energy Proc 2017;105. https://doi.org/10.1016/j.egypro.2017.03.317.

[26] Aziz M, Putranto A, Biddinika MK, Wijayanta AT. Energy-saving combination of N2 production, NH3 synthesis, and power generation. Int J Hydrogen Energy 2017;42:27174-83. https://doi.org/10.1016/J.IJHYDENE.2017.09.079.

[27] Rösch C, Skarka J, Wegerer N. Materials flow modeling of nutrient recycling in biodiesel production from microalgae. Bioresour Technol 2012;107:191-9. https:// doi.org/10.1016/j.biortech.2011.12.016.

[28] Wei L, Lu Y. Fluidization behavior in high-pressure water at temperature from ambient to supercritical. Powder Technol 2016;304:89-100. https://doi.org/10. 1016/J.POWTEC.2016.08.025.

[29] Loppinet-Serani A, Aymonier C, Cansell F. Current and foreseeable applications of supercritical water for energy and the environment. ChemSusChem 2008;1:486-503. https://doi.org/10.1002/cssc.200700167.

[30] Sricharoenchaikul V. Assessment of black liquor gasification in supercritical water. Bioresour Technol 2009;100:638-43. https://doi.org/10.1016/j.biortech.2008.07. 011.

[31] Salimi M, Safari F, Tavasoli A, Shakeri A. Hydrothermal gasification of different agricultural wastes in supercritical water media for hydrogen production: a comparative study. Int J Ind Chem 2016;7:277-85. https://doi.org/10.1007/s40090016-0091-y.

[32] Gupta P, Velazquez-Vargas LG, Fan LS. Syngas redox (SGR) process to produce hydrogen from coal derived syngas. Energy Fuels 2007;21:2900-8. https://doi.org/ 10.1021/ef060512k. 